\section{Case Reports in Dermatology}

Case Rep Dermatol 2017;9:1-5

This article is licensed under the Creative Commons Attribution-NonCommercial 4.0 International License (CC BY-NC) (http://www.karger.com/Services/OpenAccessLicense). Usage and distribution for commercial purposes requires written permission.

\title{
Papular Epidermal Nevus with "Skyline" Basal Cell Layer Syndrome - Natural Course: Case Report and Literature Review
}

\author{
Carole Anouk Zahn ${ }^{\mathrm{a}}$ Peter Itin ${ }^{\mathrm{b}, \mathrm{c}}$ \\ ${ }^{a}$ Faculty of Medicine, University of Basel, Basel, Switzerland; ${ }^{b}$ Department of Dermatology, \\ University Hospital Basel, Basel, Switzerland; 'Department of Biomedicine, University \\ Hospital Basel, Basel, Switzerland
}

\section{Keywords}

Papular epidermal nevus with "skyline" basal cell layer - Hyperkeratotic papules and plaques . Neurocutaneous syndrome · Mild mental retardation · Epileptic seizures · Gonadal mosaicism · Paradominant inheritance $\cdot$ Natural course

\begin{abstract}
Papular epidermal nevus with "skyline" basal cell layer (PENS) is a very rare type of keratinocytic nevus and is associated with extracutaneous findings such as neurological symptoms in about $50 \%$ of the cases. Therefore, it is also referred to as PENS syndrome. Clinically visible hyperkeratotic papules and plaques already appear at birth or shortly thereafter, while neurological symptoms such as epilepsy and mental retardation manifest themselves during childhood. Genetics suggests gonadal mosaicism as a possible cause for the disease. Another hypothesis is that genetic mutation can occur in a mendelian trait or through a paradominant inheritance.

(C) 2016 The Author(s)

Published by S. Karger AG, Basel
\end{abstract}




\section{Introduction}

We hypothesize that the typical skin alterations, confirmed in biopsies, in combination with the neurological symptoms that occurred in 6 out of 15 young patients describe a new neurocutaneous syndrome. Follow-up examinations has shown a benign natural course so far.

\section{Case Report}

We present a boy born in 2002 and suffering from PENS syndrome. At the first consultation in 2004 at the age of 2 years, he showed typical hyperkeratotic papules and plaques on the skin, which were already present at birth as well as various neurological symptoms such as mild mental retardation and motor clumsiness.

Family history revealed that his 1-year older brother born in 2001 suffers from the same skin lesions as our patient, although in a much more alleviated and milder form. Skin changes on the trunk and right leg of the older brother already appeared at birth and remained stable over time with a diameter of $0.5-1 \mathrm{~cm}$. No additional skin lesions appeared. The older brother did not show any further cutaneous aberrations or neurological symptoms such as psychomotor retardation or epilepsy.

Additional findings in the index case included dry, rough, and pimply looking skin as well as bad sportsmanship, as stated by his mother. Our patient also has a 4-year-old younger sister born in 2005, who neither shows typical skin lesions nor typical neurological symptoms of PENS syndrome. Nevertheless, examinations determined a dry and pimply looking skin surface just as in the eldest brother. The Parents of the 3 siblings are asymptomatic and healthy. Whole-genome sequencing has not been performed yet.

According to the mother of our patient, he already developed 3 cutaneous lesions 1 month after birth. They were reddish-yellowish, and some smaller ones that were whitish with a rough and slightly scaling surface, irregular borders, and $0.5-2 \mathrm{~cm}$ in diameter occurred later on. At follow-up examinations conducted in 2015, 18 skin lesions were found. In the meantime, the pre-existing skin lesions did grow proportionally to the boy's growth. The skin lesions were diffusely disseminated on the shoulder, neck, axilla, left upper arm, abdomen, in the gluteal and perigenital areas, and on the lower extremities (Fig. 1).

Histopathological investigation revealed an altered epidermis. Clues for the diagnosis of PENS include acanthosis with a ribbon of hyperchromatic, cuboidal, darker keratinocytes with a skyline pattern on a thickened basal cell layer. This special sign is typical for the papular epidermal nevus with "skyline" basal cell layer (PENS), which received its name from this finding. The broadened epidermis has elongated rete ridges, which are relatively slim. The stratum granulosum is sometimes missing in contrast to the stratum corneum, which shows dense hyperkeratosis with focally subcorneal abscesses of neutrophils. Additional investigation employing the marker S-100 did not show any pathological issue, although some S-100 melanocytes with perinuclear halo formation up to the middle of the epidermis were visible. The adjacent dermis is not affected, and therefore no deeper infiltration seems to occur [1] (Fig. 2).

Extracutaneous findings mainly include neurological symptoms, inter alia psychomotor delay and mild mental retardation in our case. His parents and neuropsychiatric records suggested that the psychomotor retardation had almost disappeared, and the normalized 
EEG results confirmed this assumption. The prognosis is benign, and the boy attended school with satisfactory results with the aid of remedial teachers.

As of 2016, prognosis still seems to be benign. The skin lesions remained stable, and the neurological symptoms improved without medical intervention.

\section{Discussion}

Our 14-year-old patient showed typical signs of PENS syndrome. Not only were numerous hyperkeratotic papules and plaques present and confirmed by skin biopsies but the patient also showed some typical neurological symptoms. These different manifestations indicate that PENS can affect other tissues such as the brain. The natural course of mild mental retardation and motor clumsiness is likely to be self-limiting. Due to the development during adolescence, progressive maturation of cortical activity seems to occur [2]. This assumption had been confirmed by the parents and neuropsychiatric records over the 14 years of examination. It was certainly beneficial for the development of our patient that he could be adequately supported in dealing with his neurological problems such as mild retardation.

Histopathological investigation revealed an altered epidermis. As the dermis was unaffected, we can state that no deeper infiltration seemed to occur. The typical PENS lesions were randomly distributed with accumulation on the trunk and neck. Palms and feet were spared. The cutaneous aberrations did not follow any specific pattern such as Blaschko lines as indicated in another case [3]. The invisibility of the migrations of embryonic cells is a normal condition and separates itself from genetic skin disorders such as focal dermal hypoplasia [4]. Although skin alterations did grow proportionally to the boy's growth, they remained stable over time. They were completely asymptomatic as in all cases reported so far. Only due to the disturbing hyperkeratosis of the papules and plaques, therapy with a keratolytic agent (Carbamid) was initiated in our case. Since the patient did not show epileptic seizures, which could have been extenuated with drug therapy, no additional treatment seemed to be necessary.

The investigation of family members was otherwise mostly without any pathological findings, neither in the siblings nor in the parents with the exception of 3 small asymptomatic similar skin lesions in the older brother. Therefore, we suppose that gonadal mosaicism was present in 1 out of the 2 unaffected parents and resulted in the transmission of genetic alteration to the younger child [5]. Another hypothesis is that they could have inherited their genetic mutation in a mendelian trait or through a paradominant inheritance [5]. The phenomenon of the "loss of heterozygosity", also known as "type 2 mosaicism" as stated by Tadini and Castori [6], confirms that the mutation as it is seen in PENS syndrome compared with type 1 mosaicism consists of a "second hit during prenatal life on the wt (i.e. wild-type) allele inherited from the unaffected gamete". However, affected patients should not be concerned about the genetic risk for their offspring due to the independence and nonautomatic transfer to their child [6].

The fact that not all affected individuals with skin lesions in familial cases also suffer from neurological symptoms suggests that the phenotype can differ among family members carrying the same germline mutation. 


\section{Conclusion}

Hyperkeratotic papules and plaques histopathologically identified as papular epidermal nevus with 'skyline' basal cell layer (PENS) in combination with neurological symptoms such as mental retardation or epilepsy lead to the diagnosis of PENS syndrome. However, not all patients show the full-blown clinical picture. Skin aberrations identified with skin biopsy on its own can also lead to the diagnosis of PENS. However, dermatologists should also include the report from neurologists and parents [7].

In most cases, PENS syndrome seems to develop sporadically, while familial occurrence is reported only rarely [8]. Whole-genome sequencing has not yet been performed in our case. However, there are several hypotheses including gonadal mosaicism and paradominant inheritance [9].

PENS syndrome in our patient showed a benign, natural course with improvement of the neurological symptoms and stabilization of the skin changes over time. Due to this selflimiting trend, no therapy was required. As the disease still flares up from time to time, further investigation is needed to confirm our assumptions.

\section{Statement of Ethics}

The authors confirm that informed consent of the patient was obtained. The research complies with all ethical guidelines for human studies and animal welfare regulations.

\section{Disclosure Statement}

The authors declare that there are no conflicts of interests to disclose.

\section{References}

1 Happle R: Paradominant inheritance: a possible explanation for Becker's pigmented hairy nevus. Eur J Dermatol 1992;2:39-40.

-2 Itin P, Tadini G, Restano L, Happle R: PENS syndrome: a new neurocutaneous phenotype. Dermatology 2012;224:24-30.

-3 Faure E, Tadini G, Brena M, et al: Papular epidermal nevus with "skyline" basal cell layer (PENS) following a Blaschko linear pattern. Pediatr Dermatol 2013;30:e270-e371.

4 Torrelo A, Colmenero I, Kristal L, et al: Papular epidermal nevus with "skyline" basal cell layer (PENS). J Am Acad Dermatol 2011;64:888-892.

-5 Brena M, Tadini G, et al: Familial papular epidermal nevus with "skyline" basal cell layer. Pediatr Dermatol 2014;31:e33-e35.

6 Tadini G, Castori M: Discoveries and controversies in cutaneous mosaicism. G Ital Dermatol Venereol 2016;151:251-265.

7 Rodriguez-Diaz E, Torrelo A, et al: Papular epidermal nevus with “'skyline"' basal cell layer (PENS) with extracutaneous findings. Pediatr Dermatol 2013;30:e54-e56.

8 Caputo R, Tadini G: Atlas of Genodermatoses. London/New York, Taylor and Francis, 2006.

$\checkmark 9$ Spinner NB, Conlin LK: Mosaicism and clinical genetics. Am J Med Genet Part C Semin Med Genet 2014;166C:397-405. 


\section{Case Reports in Dermatology}

\begin{tabular}{l|l}
\hline Case Rep Dermatol 2017;9:1-5 \\
\hline DOI: 10.1159/000454757 & $\begin{array}{l}\text { @ 2016 The Author(s). Published by S. Karger AG, Basel } \\
\text { www.karger.com/cde }\end{array}$ \\
\hline
\end{tabular}

Zahn and Itin: Papular Epidermal Nevus with "Skyline" Basal Cell Layer Syndrome Natural Course: Case Report and Literature Review

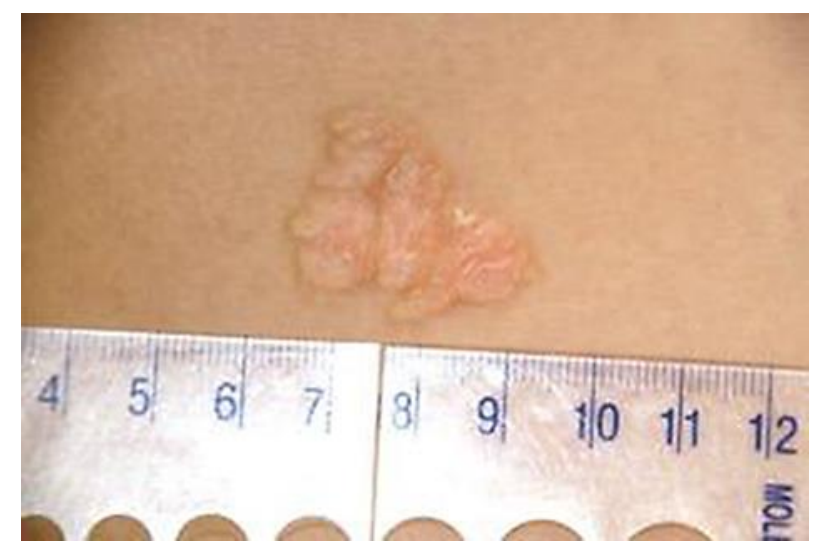

Fig. 1. A typical PENS plaque is shown.

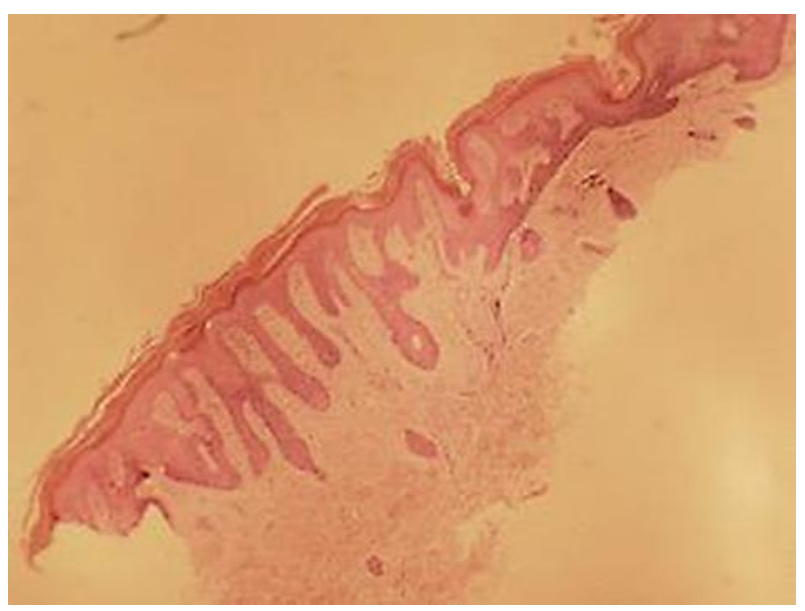

Fig. 2. Histopathology of PENS. 